\title{
AVALIAÇÃO NUTRICIONAL DE DIETAS DE TRABALHADORES EM RELAÇÃO A PROTEÍNAS, LIPÍDEOS, CARBOIDRATOS, FIBRAS ALIMENTARES E VITAMINAS ${ }^{1}$
}

\author{
Vera Akiko MAIHARA2,*, Marta Gomes SILVA³, Vera Lúcia Signoreli BALDINI ${ }^{3}$, \\ Ana Maria Rauen MIGUEL ${ }^{3}$, Déborah Inês Teixeira FÁVARO ${ }^{2}$
}

\begin{abstract}
RESUMO
Estudos sobre composição de alimentos largamente consumidos pela população são fundamentais para estabelecer se uma determinada dieta é adequada em relação aos nutrientes essenciais. No presente trabalho, são apresentados resultados de análises de nutrientes realizadas em dietas representativas do consumo alimentar de trabalhadores de indústria de autopeças da cidade de São Paulo (homens de 19 a 56 anos), coletadas a partir da porção em duplicata de todos os alimentos e bebidas consumidos durante 3 dias consecutivos. Foram determinados os teores de proteínas, lipídeos, carboidratos, cinza, umidade, fibras alimentares e vitaminas B1, B2 e piridoxina em 24 dietas. Comparando-se os resultados obtidos com as novas recomendações (DRIs), verificou-se que as dietas dos trabalhadores atingiram adequação de $100 \%$ em carboidratos e $96 \%$ em proteínas e lipídeos. Em relação às fibras dietéticas, as dietas foram inadequadas, com apenas $4,2 \%$ de adequação. Todas as dietas foram adequadas em vitaminas B1 e B2, enquanto que $58 \%$ das dietas foram inadequadas em relação à piridoxina.

Palavras-chave: ingestão dietética, dieta da porção em duplicata, composição centesimal.
\end{abstract}

\section{SUMMARY}

NUTRITIONAL EVALUATION OF PROTEINS, LIPIDS, CARBOHYDRATES, FIBER AND VITAMINS IN INDUSTRY WORKER'S DIETS. The analysis of food consumed by a large part of the population is important to establish the nutritional composition of diets to verify if diets are adequate regarding essential nutrients. In the present study, diet analysis results of steel industry workers ' dietary consumption are presented. Workers from 19 to 56 years old were selected and their diets were collected by a duplicate portion technique, including all the meals and beverages consumed over 3 consecutive days. The content of lipids, proteins, carbohydrates, ash, humidity, fiber, vitamins B1 and B2 and piridoxine were determined in 24 diet samples. Comparing the results with the values set by the new dietary recommendation dietary intakes (DRIs), it was observed that the workers' diets were $100 \%$ adequate in carbohydrates and $96 \%$ in proteins and lipids. However, dietetic fiber content of the diets was considered inadequate (only $4.2 \%$ of adequacy). All the diets were adequate in $\mathrm{B} 1$ and $\mathrm{B} 2$ vitamins, while $58 \%$ of the diets were inadequate in terms of piridoxine.

Keywords: dietetic intake, duplicate portion diet; proximate composition.

\section{1 - INTRODUÇÃO}

Cada vez mais a população, de um modo geral, tem-se preocupado com a qualidade dos alimentos consumidos, tanto em relação ao seu aspecto nutricional quanto aos possíveis efeitos maléficos que possam afetar diretamente a qualidade de vida [5].

Uma dieta adequada reduz o número de doenças, diminuindo, portanto, os gastos públicos com o tratamento de doenças relacionadas com as deficiências nutricionais. Mudanças nos hábitos alimentares e nos padrões de dietas que envolvem crescente consumo de alimentos refinados, também têm levado à deficiência de vários nutrientes, notadamente algumas vitaminas, fibras e alguns elementos traço como zinco e cromo [9].

\footnotetext{
${ }^{1}$ Recebido para publicação em 17/11/2005. Aceito para publicação em 6/7/2006 (001639)

${ }^{2}$ Instituto de Pesquisas Energéticas e Nucleares (IPEN-CNEN/SP), Avenida Prof. Lineu Prestes, 2242, (USP),

CEP 05508-000, São Paulo, Brasil,

E-mail:vmaihara@ipen.br

${ }^{3}$ Centro de Química de Alimentos e Nutrição Aplicada (ITAL),

Avenida Brasil, 2880, CEP 13070-178, Campinas (SP)

* A quem a correspondência deve ser enviada
}

A determinação dos teores de proteínas, lipídeos, cinzas, carboidratos, fibras e vitaminas permitem avaliar se as dietas são adequadas ou não sob o ponto de vista nutricional e calórico aos grupos a que se destinam.

As proteínas, carboidratos, lipídeos e álcool são os componentes dos alimentos que contribuem para o fornecimento de energia (calorias) para a dieta. A energia é necessária para sustentar várias funções no corpo, incluindo respiração, circulação, trabalho físico e síntese protéica.

Os carboidratos fornecem energia às células do corpo, particularmente ao cérebro, que é um órgão dependente desse nutriente. Lipídeos, a maior fonte de energia para o corpo, ajudam na absorção de vitaminas A, D, E e K lipossolúveis e outros componentes como os carotenóides. As proteínas, maiores componentes estruturais de todas as células do corpo humano, são importantes para a construção e manutenção dos tecidos, formação de enzimas, hormônios, anticorpos, na regulação de processos metabólicos, além de fornecer energia.

As fibras dietéticas são de grande interesse, uma vez que dietas ricas em fibras estão associadas a melhor saúde do cólon, incidência reduzida de diabetes em adultos e pressão arterial e nível de colesterol menores. Dietas ricas 
em frutas e vegetais fornecem fibras necessárias para o bom funcionamento do intestino.

A Tiamina (vitamina B1) é essencial para ajudar as células a converterem carboidrato em energia e é necessária para o bom funcionamento das células nervosas e do cérebro. A Riboflavina (vitamina B2) ajuda as células a converterem carboidrato em energia e é essencial para o crescimento das células, produção das células vermelhas e para a saúde dos olhos e da pele. A piridoxina é necessária para a função do cérebro e a formação das células vermelhas; está envolvida na função imunológica e na atividade hormonal.

Estudos de composição dos alimentos largamente consumidos pela população são importantes para estabelecer se uma determinada dieta é adequada em relação aos nutrientes essenciais.

No Brasil, poucos grupos de pesquisa estão direcionados na avaliação do estado nutricional de grupos populacionais pela análise química direta de dietas por meio da técnica de amostragem da porção em duplicata $[7,8,10,11]$.

O presente trabalho tem como objetivo avaliar a adequação nutricional de dietas consumidas por trabalhadores de indústria de autopeças (homens de 19 a 56 anos) da cidade de São Paulo. As dietas foram coletadas a partir da porção em duplicata de todos os alimentos e bebidas consumidos durante 3 dias consecutivos. Foram determinados os teores de proteínas, lipídeos, carboidratos, cinza, umidade, fibras alimentares e vitaminas B1, B2 e piridoxina. Os resultados obtidos foram convertidos em dados de ingestão e comparados às novas recomendações (DRIs), para verificar a adequação das dietas em relação aos nutrientes determinados $[3,4]$.

\section{2 - MATERIAL E MÉTODOS}

\section{1 - Grupo estudado: trabalhadores}

O grupo estudado constituiu-se de trabalhadores de uma indústria de autopeças da cidade de São Paulo. Foram escolhidos 24 trabalhadores, entre os que se interessaram em participar do estudo, do sexo masculino, com idades variando entre 19 e 56 anos.

\section{2 - Coleta das dietas dos trabalhadores pelo método da porção em duplicata}

As dietas foram coletadas durante três dias no próprio refeitório da empresa no almoço e jantar, utilizando-se o método da porção em duplicata [6].

Foram coletadas duplicatas de todas as refeições servidas no refeitório da indústria, em bandejas identificadas, contendo quantidades de alimento iguais às inicialmente coletadas pelos trabalhadores, descontando-se, no final de cada refeição, o que não foi consumido. Os alimentos que foram consumidos pelos trabalhadores fora da empresa, também foram acrescidos às dietas coletadas na indústria.
Durante todo o processo de coleta, todos os alimentos de cada trabalhador foram pesados em balança semi-analítica no próprio refeitório da empresa, em seguida, armazenados em potes de polietileno para cada tipo de alimento. Esses potes foram previamente lavados com água, detergente neutro e deixados em solução de ácido nítrico $20 \%$ por $24 \mathrm{~h}$. Em seguida, os potes foram lavados com bastante água deionizada.

Após a coleta, todas as dietas passaram por um processo de preparação antes de serem analisadas.

\section{3 - Preparação das dietas}

Inicialmente os alimentos coletados foram homogeneizados. Esta homogeneização consistiu no agrupamento de todos os alimentos sólidos como carnes, legumes, arroz, feijão e frutas, juntamente com os líquidos (bebidas consumidas), para então serem triturados em moinho de facas.

Após a homogeneização, as dietas foram congeladas e em seguida liofilizadas em um liofilizador marca Atlas Mark, com capacidade para 500 L na indústria Liotécnica, de alimentos liofilizados.

A fim de se obter uma melhor homogeneização, as dietas foram novamente trituradas em um multiprocessador doméstico.

Após o término da preparação, foram obtidas amostras de dietas em forma de pó de cada trabalhador, para assim serem analisadas.

\section{4 - Metodologias utilizadas}

\subsection{1 - Umidade}

O teor de umidade foi determinado pelo método de secagem das amostras até peso constante, em estufa a $105^{\circ} \mathrm{C}$.

\subsection{2 - Cinzas}

As cinzas foram determinadas na amostra após completa carbonização em bico de Bunsen, seguida de incineração em mufla a $550{ }^{\circ} \mathrm{C}$, até a obtenção de um resíduo isento de carvão, com coloração branca ou acinzentada [2].

\subsection{3 - Lipídios totais}

Os lipídios foram determinados pelo teor de substâncias solúveis em éter etílico, após tratamento prévio com ácido clorídrico [2].

\subsection{4 - Proteína bruta}

O teor de nitrogênio total foi determinado segundo o método de Kjeldahl. O teor de proteína total foi calculado multiplicando-se o valor do nitrogênio total por 6,25 [2]. 


\subsection{5 - Fibra alimentar total}

O teor de fibra alimentar total foi determinado pelo método enzimático/gravimétrico (Método AOAC 985.29) [2]. Esse método baseia-se na gelatinização e hidrólise parcial do amido com uma alfa-amilase termorresistente, seguida de hidrólise da proteína com uma protease e hidrólise do amido residual com uma amiloglucosidase. Em seguida, a porção fibra foi precipitada pela adição de etanol 95\%, seguido de filtração e lavagem do resíduo com solventes. Após secagem e pesagem dos resíduos, foi feita a determinação de proteína e cinzas no resíduo [2, 13].

\subsection{6 - Carboidratos}

O teor de carboidratos foi determinado por diferença, subtraindo-se de $100 \%$ a soma dos valores obtidos nas determinações anteriores.

\subsection{7 - Calorias}

O valor calórico das dietas foi calculado pela soma das porcentagens de proteína bruta e carboidratos, multiplicados pelo fator $4\left(\mathrm{Kcal} \mathrm{g}^{-1}\right)$, somado ao teor de lipídios totais, multiplicado pelo fator $9\left(\mathrm{Kcal} \mathrm{g}^{-1}\right)$.

\subsection{8 - Vitaminas}

No preparo das amostras para tiamina (Vitamina B1) e riboflavina (Vitamina B2), foram adicionados $40 \mathrm{~mL}$ de ácido clorídrico $0,01 \mathrm{moL} \mathrm{L}^{-1}$ a 2,5 g de amostra, seguido de autoclavagem por $15 \mathrm{~min}$. Após correção do $\mathrm{pH}$ para 4,5 com acetato de sódio $20 \%$, adicionou-se papaína, diástase e tolueno, hidrolisando-se as amostras por uma noite à temperatura ambiente. Após a hidrólise, foram filtradas em papel e em membranas de 0,45 $\mu \mathrm{m}$, antes de injeção no cromatógrafo líquido [1].

Para as análises de vitaminas B1 e B2, utilizou-se coluna de $\mathrm{C} 18$, de $15 \mathrm{~cm}$ de comprimento e partículas de $5 \mu \mathrm{m}$, e detector de fluorescência, sendo que a vitamina B1 sofreu derivação pós coluna. A fase móvel usada para B1 e B2 consistiu de cloreto de potássio 0,038 $\mathrm{mol} \mathrm{L}^{-1}$ e metanol (70/30).

A piridoxina (Vitamina B6) foi extraída com ácido clorídrico $0,44 \mathrm{moL} \mathrm{L}^{-1} \mathrm{em}$ autoclave por $2 \mathrm{~h}$ e o $\mathrm{pH}$ foi corrigido com hidróxido de sódio $6 \mathrm{moL} \mathrm{L} \mathrm{L}^{-1}$. As amostras foram filtradas em papel filtro Whatman $\mathrm{n}^{\circ} 42$ e em membranas de $0,45 \mu \mathrm{m}$ de poro, antes de serem injetadas no cromatógrafo líquido.

Para a piridoxina, foi utilizado coluna C18 de $15 \mathrm{~cm}$ de comprimento e partículas de $5 \mu \mathrm{m}$, detector de fluorescência e a solução de fosfato de potássio $0,033 \mathrm{moL} \mathrm{L}^{-1} \mathrm{pH} \mathrm{2,2}$ foi utilizada como fase móvel.

\section{3 - RESULTADOS E DISCUSSÃO}

A necessidade estimada de energia (EER - Estimated Energy Requirement) é definida como a ingestão dietética média de energia que é necessária para manter o balanço de energia em uma pessoa saudável, considerando-se a idade, peso, altura, sexo e o nível da atividade física. Este valor de referência foi calculado para cada participante, segundo as novas recomendações [ 3].

No grupo de trabalhadores, os participantes foram classificados como pouco ativos, apenas um ( $\left.n^{\circ} 24\right)$ foi considerado muito ativo, pois se tratava de um maratonista. Na Tabela 1, são apresentados os dados antropométricos dos participantes do estudo, a quantidade consumida, os valores de umidade e cinzas, assim como as necessidades em energia, calculados para a dieta coletada.

As novas recomendações para carboidratos foram estabelecidas, para diferentes faixas etárias. Na faixa etária estudada no presente trabalho, de 19 a 51 anos de idade e para ambos os sexos, os novos valores de DRIs [3] recomendam valores de EAR (Estimated Average Requirement) de $100 \mathrm{~g} /$ dia e de $130 \mathrm{~g} /$ dia para RDA (Recommended Dietary Allowance) [3].

Para proteína, foram estabelecidas novas recomendações de 0,8 g de proteína de boa qualidade/kg de peso corpóreo/dia [3].

A Tabela 2 apresenta os valores de ingestão diária determinados nas dietas dos trabalhadores para carboidratos e proteínas e sua adequação em relação aos novos valores preconizados pelas DRIs [3].

Considerando os valores preconizados pelas novas DRIs [3], todas as dietas dos trabalhadores atingiram adequação de $100 \%$ em carboidratos e cerca de $96 \%$ das dietas foram adequadas em proteína. Resultados semelhantes foram obtidos por FÁVARO et al. [7] que analisaram dietas regionais dos Estados de Santa Catarina e Mato Grosso e da cidade de Manaus, porém todas as dietas mostraram-se deficientes em energia. YUYAMA et al. [14] analisaram dietas em duplicata de pré-escolares de duas regiões Amazônicas, que apresentaram uma adequação energética baixa ( $10 \%$ a $21,5 \%$ ) e a adequação protéica foi inferior a $80 \%$.

Uma deficiência de proteínas raramente ocorre isolada à deficiência de outros nutrientes. Deficiência prolongada de proteína resulta em debilitação do organismo e desnutrição. Dietas ricas em proteínas não são tóxicas.

Para lipídeos, a maior fonte de energia para o corpo, nenhum valor de $E A R$ e de RDA foi estabelecido. Para a avaliação de lipídeos, são utilizados os valores de $A M D R$ (Acceptable Macronutrients Distribution Ranges) [3]. Também foram atribuídos valores de AMDR para carboidratos, proteínas, ácidos graxos poliinsaturados n-6 e n-3. Os intervalos de valores de AMDR para lipídeos e carboidratos foram estimados na faixa de $20 \%$ a $35 \%$ e de $45 \%$ a $65 \%$ de energia para adultos, respectivamente. Estes valores foram baseados em evidência, indicando um risco para as doenças coronarianas em níveis baixos de lipídeos e altas ingestões de carboidratos. Também foram baseados em evidências quanto ao risco elevado para obesidade e suas implicações, incluindo as doenças coronarianas, com altas ingestões de 
TABELA 1 - Dados antropométricos e valores de umidade, cinzas e EER calculados nas dietas dos trabalhadores.

\begin{tabular}{|c|c|c|c|c|c|c|c|c|c|}
\hline Participante & Idade (anos) & Peso (kg) & Altura (m) & $\begin{array}{c}\text { Consumo } \\
\text { (g/dia) }\end{array}$ & $\begin{array}{c}\text { Umidade } \\
\text { (g/dia) }\end{array}$ & $\begin{array}{l}\text { Cinzas } \\
\text { (g/dia) }\end{array}$ & kcal/dia & $E E R$ (kcal) & $\begin{array}{c}\text { Adequação } \\
\%\end{array}$ \\
\hline 1 & 30 & 59,2 & 1,63 & 451 & 23 & 18 & 1911 & 2395 & 79,8 \\
\hline 2 & 42 & 78,4 & 1,65 & 335 & 20 & 15 & 1436 & 2635 & 54,5 \\
\hline 3 & 20 & 71,8 & 1,79 & 543 & 18 & 22 & 2340 & 2809 & 83,3 \\
\hline 4 & 27 & 84,2 & 1,80 & 543 & 17 & 25 & 1974 & 2970 & 66,5 \\
\hline 5 & 35 & 80,0 & 1,71 & 433 & 21 & 17 & 1778 & 2765 & 64,3 \\
\hline 6 & 27 & 72,0 & 1,75 & 572 & 17 & 22 & 2461 & 2724 & 90,3 \\
\hline 7 & 33 & 91,1 & 1,74 & 455 & 42 & 21 & 1780 & 2999 & 59,4 \\
\hline 8 & 35 & 61,1 & 1,55 & 427 & 17 & 18 & 1744 & 2336 & 74,6 \\
\hline 9 & 32 & 72,3 & 1,78 & 782 & 23 & 31 & 3380 & 2700 & 125,2 \\
\hline 10 & 30 & 69,5 & 1,81 & 714 & 19 & 24 & 3186 & 2685 & 118,7 \\
\hline 11 & 40 & 91,5 & 1,78 & 619 & 31 & 25 & 2614 & 2963 & 88,2 \\
\hline 12 & 35 & 90,5 & 1,79 & 538 & 17 & 22 & 2260 & 2987 & 75,6 \\
\hline 13 & 56 & 75,2 & 1,63 & 403 & 18 & 15 & 1652 & 2429 & 68,0 \\
\hline 14 & 23 & 108,6 & 1,80 & 599 & 19 & 23 & 2576 & 3439 & 74,9 \\
\hline 15 & 26 & 64,2 & 1,86 & 632 & 23 & 28 & 2716 & 2656 & 102,3 \\
\hline 16 & 19 & 67,5 & 1,68 & 479 & 19 & 19 & 1970 & 2676 & 73,6 \\
\hline 17 & 32 & 81,9 & 1,71 & 512 & 17 & 16 & 2284 & 2825 & 80,8 \\
\hline 18 & 36 & 90,8 & 1,78 & 522 & 23 & 21 & 2186 & 2986 & 73,2 \\
\hline 19 & 21 & 63,7 & 1,71 & 477 & 17 & 19 & 2016 & 2611 & 77,2 \\
\hline 20 & 34 & 71,5 & 1,74 & 474 & 21 & 17 & 2027 & 2643 & 76,7 \\
\hline 21 & 31 & 94,2 & 1,76 & 336 & 17 & 15 & 1490 & 3081 & 48,4 \\
\hline 22 & 33 & 93,3 & 1,75 & 424 & 24 & 16 & 1714 & 3040 & 56,4 \\
\hline 23 & 46 & 80,8 & 1,57 & 424 & 19 & 16 & 1760 & 2591 & 67,9 \\
\hline 24 & 41 & 66,2 & 1,65 & 609 & 32 & 27 & 2393 & 3143 & 76,1 \\
\hline
\end{tabular}

TABELA 2 - Valores de ingestão e de \% de adequação de carboidratos e proteínas, nas dietas dos trabalhadores.

\begin{tabular}{|c|c|c|c|c|c|}
\hline \multirow[t]{2}{*}{ Dieta } & \multicolumn{2}{|c|}{ Carboidratos } & \multicolumn{3}{|c|}{ Proteínas } \\
\hline & g/dia & $\%$ adequação & g/dia & g/kg p.c./dia & $\%$ adequação \\
\hline 1 & 242 & 242 & 78 & 1,31 & 164 \\
\hline 2 & 165 & 165 & 68 & 0,87 & 109 \\
\hline 3 & 278 & 278 & 102 & 1,42 & 177 \\
\hline 4 & 338 & 338 & 100 & 1,19 & 149 \\
\hline 5 & 247 & 247 & 71 & 0,89 & 111 \\
\hline 6 & 330 & 330 & 105 & 1,46 & 183 \\
\hline 7 & 226 & 226 & 95 & 1,04 & 130 \\
\hline 8 & 224 & 224 & 88 & 1,43 & 179 \\
\hline 9 & 438 & 438 & 135 & 1,86 & 233 \\
\hline 10 & 410 & 410 & 130 & 1,88 & 234 \\
\hline 11 & 338 & 338 & 115 & 1,26 & 157 \\
\hline 12 & 285 & 285 & 116 & 1,29 & 161 \\
\hline 13 & 223 & 223 & 86 & 1,15 & 144 \\
\hline 14 & 322 & 322 & 133 & 1,23 & 153 \\
\hline 15 & 343 & 343 & 120 & 1,87 & 234 \\
\hline 16 & 266 & 266 & 99 & 1,47 & 184 \\
\hline 17 & 293 & 293 & 84 & 1,03 & 128 \\
\hline 18 & 280 & 280 & 107 & 1,17 & 147 \\
\hline 19 & 261 & 261 & 100 & 1,57 & 197 \\
\hline 20 & 265 & 265 & 78 & 1,10 & 137 \\
\hline 21 & 145 & 145 & 88 & 0,93 & 117 \\
\hline 22 & 210 & 210 & 105 & 1,13 & 141 \\
\hline 23 & 205 & 205 & 98 & 1,22 & 152 \\
\hline 24 & 342 & 342 & 101 & 1,53 & 191 \\
\hline
\end{tabular}

lipídeos [3]. A faixa de $A M D R$ para proteínas é de 10\% a 35\% de energia para os adultos.

Os valores médios obtidos para a ingestão dietética diária para carboidratos, lipídeos e proteínas, calculados em relação à energia, encontram-se na Tabela 3 , com os respectivos valores de $A M D R$.

TABELA 3 - Valores de lipídeos, carboidratos e proteínas em energia (\%), nas dietas.

\begin{tabular}{lccc}
\hline & \multicolumn{2}{c}{ Dietas dos trabalhadores } & \\
\cline { 2 - 3 } & $\begin{array}{c}\text { Média } \pm \text { DP } \\
\text { (\% em energia) }\end{array}$ & $\begin{array}{c}\text { Intervalo } \\
\text { (\% em energia) }\end{array}$ & $\begin{array}{c}\text { AMDR } \\
\text { (\% em energia) }\end{array}$ \\
\hline Lipídeos & $30 \pm 5$ & $11-37$ & 20 a 35 \\
Carboidratos & $52 \pm 5$ & $39-68$ & 45 a 65 \\
Proteínas & $19 \pm 3$ & $15-25$ & 10 a 35 \\
\hline DP: desvio padrão. & \multicolumn{3}{|}{}
\end{tabular}

Em relação a estes nutrientes analisados, 92\% das dietas apresentaram valores de porcentagem em energia adequados, com exceção de uma dieta que não atingiu a faixa de distribuição adequada para lipídeos e ultrapassou o máximo para carboidrato.

As fibras dietéticas consistem de carboidratos não digeríveis e ligninas, que são intrínsecas e intactas em plantas. A fibra funcional consiste de carboidratos não digeríveis isolados, que têm efeitos fisiológicos benéficos em seres humanos. A fibra total é a soma das fibras dietéticas e funcionais [3].

Um valor de ingestão adequada (AI - Adequate Intake) para fibra total em alimentos foi estimado em $38 \mathrm{~g} /$ dia, para 
homens, e de 25 g/dia, para mulheres. Estes valores foram baseados em níveis de ingestão que podem proteger contra doenças coronarianas.

A Tabela 4 apresenta a ingestão diária de fibra, vitaminas B1, B2, piridoxina com as respectivas adequações nas dietas dos trabalhadores.

Pelos resultados, pode-se observar que apenas uma dieta $\left(n^{\circ} 4\right)$ apresentou ingestão adequada em relação às fibras totais. As dietas brasileiras normalmente são pobres em fibras, como observado em vários trabalhos, que também utilizaram a amostragem em porção em duplicata [12].

A necessidade dietética recomendada para a Timina é de $1,2 \mathrm{mg} /$ dia para homens e 1,1 mg/dia para mulheres [4]. As melhores fontes de vitamina B1 são carne de porco, bacon, presunto, peixe e produtos de grãos enriquecidos.

O valor de $R D A$ é de 1,3 e 1,1 mg/dia para homens e mulheres, respectivamente [4]. As melhores fontes de vitamina B2 são os órgãos, como o fígado, rim e coração, amêndoas, fermento e ostras.

O valor de $R D A$ para a piridoxina (vitamina B6) é de $1,3 \mathrm{mg} /$ dia para homens na faixa de 14 a 50 anos e mulheres entre 19 e 50 anos. As principais fontes de vitamina B6 são: fígado, aves, peixes, nozes e frutas.

Deficiências suaves de tiamina resultam na falta de concentração, irritabilidade, depressão e fraqueza muscular. A deficiência de riboflavina pode ocorrer em combinação com a deficiência de outras vitaminas do complexo B. Sintomas de sua deficiência incluem boca inflamada com fissuras, pele seca, confusão mental. Em relação à ingestão deficiente de B6, os sintomas perceptíveis são: feridas na pele, língua e boca; náusea; nervosismo; e convulsões. Não há registro na literatura de efeitos tóxicos para a ingestão elevada de tiamina e riboflavina.

Neste trabalho, apenas uma dieta não foi adequada em relação à vitamina B1 (96\% foram adequadas); 87\% das dietas estudadas foram deficientes em B2; e 58\% deficientes em piridoxina.

Dados de ingestão dietética das vitaminas B1, B2 e piridoxina em dietas são escassos na literatura. Desse modo, os resultados obtidos no presente estudo constituem uma importante contribuição para o conhecimento dos teores desses nutrientes em dietas brasileiras.

\section{4 - CONCLUSÃo}

Considerando-se os valores preconizados pelas DRIs, as dietas dos trabalhadores atingiram $100 \%$ de adequação em carboidratos, 96\% em proteína, porém se apresentaram inadequadas em calorias.

Em geral, as dietas dos trabalhadores apresentaram-se inadequadas em fibra dietética, com apenas $4,2 \%$ de adequação. Em relação às vitaminas, as dietas mostraram-se adequadas à B1 e deficientes em B2 e piridoxina.

TABELA 4 - Ingestão de fibra, vitaminas B1, B2, piridoxina nas dietas dos trabalhadores.

\begin{tabular}{|c|c|c|c|c|c|c|c|c|}
\hline \multirow[t]{3}{*}{ Dieta } & \multirow{2}{*}{\multicolumn{2}{|c|}{ Fibras }} & \multicolumn{6}{|c|}{ Vitaminas } \\
\hline & & & \multicolumn{2}{|c|}{ Tiamina (B1) } & \multicolumn{2}{|c|}{ Riboflavina (B2) } & \multicolumn{2}{|c|}{ Piridoxina (B6) } \\
\hline & g/dia & $\%$ adequação & g/dia & \% adequação & g/dia & \% adequação & g/dia & $\%$ adequação \\
\hline 1 & 19,2 & 51 & 2,43 & 203 & 0,77 & 59 & 0,54 & 42 \\
\hline 2 & 9,9 & 26 & 1,64 & 137 & 0,77 & 59 & 0,33 & 26 \\
\hline 3 & 31,9 & 84 & 2,88 & 240 & 0,98 & 75 & 0,49 & 38 \\
\hline 4 & 39,9 & 105 & 9,24 & 770 & 0,71 & 54 & 1,30 & 100 \\
\hline 5 & 20,9 & 55 & 2,04 & 170 & 0,74 & 57 & 3,04 & 234 \\
\hline 6 & 18,1 & 48 & 2,75 & 229 & 0,97 & 75 & 3,09 & 238 \\
\hline 7 & 15,8 & 41 & 2,50 & 209 & 0,59 & 46 & 3,01 & 231 \\
\hline 8 & 25,5 & 67 & 2,52 & 210 & 0,47 & 36 & 1,79 & 138 \\
\hline 9 & 34,0 & 90 & 4,54 & 378 & 1,41 & 108 & 2,97 & 229 \\
\hline 10 & 17,1 & 45 & 3,86 & 321 & 1,07 & 82 & 2,36 & 181 \\
\hline 11 & 20,9 & 55 & 3,72 & 310 & 0,99 & 76 & 2,11 & 162 \\
\hline 12 & 25,7 & 68 & 3,60 & 300 & 0,54 & 41 & 2,37 & 182 \\
\hline 13 & 14,2 & 37 & 2,26 & 188 & 0,32 & 25 & 0,44 & 34 \\
\hline 14 & 18,1 & 48 & 0,30 & 25 & 0,30 & 23 & 0,48 & 37 \\
\hline 15 & 22,2 & 58 & 4,23 & 353 & 1,39 & 107 & 0,69 & 53 \\
\hline 16 & 19,4 & 51 & 2,92 & 244 & 0,81 & 63 & 0,43 & 33 \\
\hline 17 & 16,1 & 42 & 4,30 & 358 & 1,18 & 91 & 0,26 & 20 \\
\hline 18 & 19,8 & 52 & 4,80 & 400 & 0,63 & 48 & 0,37 & 28 \\
\hline 19 & 16,6 & 44 & 4,15 & 346 & 1,00 & 77 & 0,48 & 37 \\
\hline 20 & 19,5 & 51 & 2,51 & 209 & 1,18 & 91 & 0,57 & 44 \\
\hline 21 & 8,9 & 23 & 1,88 & 157 & 0,64 & 49 & 0,34 & 26 \\
\hline 22 & 18,5 & 49 & 4,03 & 336 & 1,36 & 104 & 1,44 & 111 \\
\hline 23 & 24,6 & 65 & 4,66 & 389 & 0,55 & 42 & 0,47 & 36 \\
\hline 24 & 37,4 & 98 & 3,78 & 315 & 0,97 & 75 & 0,67 & 52 \\
\hline
\end{tabular}




\section{5 - REFERÊNCIAS BIBLIOGRÁFICAS}

[1] ASSOCIATION OF OFFICIAL ANALYTICAL CHEMISTS, Official Methods of AOAC INTERNATIONAL, GAITHERSBURG, MARYLAND, $16^{\text {th }}$ ed, Chapter 9, p, 16, 1995.

[2] CUNNIFF, P. (Ed.) Official methods of analysis of the Association of Official Analytical Chemists - AOAC, $16^{\circ}$ edição, Arlington, Virginia, 1998 ( Método 985.29).

[3] DRI, Institute of Medicine, Dietary reference intakes for Energy, Carbohydrates, Fiber, Fat, Fatty Acids, Cholesterol, Protein and Amino Acids (Macronutrients), http://www.nap.edu, copyright 2002, The National Academy of Science.

[4] DRI, Institute of Medicine, Dietary reference intakes for Thiamin, Riboflavin, Niacin, Vitamin B6, Folate, Vitamin B12, Pantothenic Acid, Biotin and Choline, http://www.nap.edu, copyright 1998, The National Academy of Science.

[5] DUTRA-DE-OLIVEIRA, J. O.; MARCHINI, J. S. Ciências Nutricionais, Savier, São Paulo, 1998.

[6] FAO/WHO - Guidelines for the study of dietary intakes of chemical contaminants. Geneva: WHO Offset Publication, n. 87, 1985.

[7] FÁVARO, D. I. T.; HUI,M. L. T.; COZZOLINO, S. M. F.; MAIHARA, V. A.; ARMELIN,M. J. A.; VASCONCELLOS, M. B. A.; YUYAMA, L. K.; BOAVENTURA, G.T.; TRAMAONTE, V.L. "Determination of various nutrients and toxic elements in different Brazilian regional diets by neutron activation analysis". J. Trace Elements Med. Biol., v. 11, n. 3, p. 129-136, 1997.

[8] FÁVARO, D. I. T.; MAIHARA, V. A.; SOUZA, S. A.; VASCONCELLOS, M. B. A.; CORDEIRO, M. B.; COZZOLINO, S. M. F. Application of neutron activation analysis to the determination of mineral and trace elements in Brazilian diets at IPEN/CNEN/SP. J. Radioanal. Nucl. Chem., v. 244, n. 1, p. 241-245, 2000.
[9] HANDS, E. S. Nutrients in Food. Lippincott Williams \& Wilkins, Baltimore, USA, 1999.

[10] MAIHARA, V. A.; VASCONCELLOS, M. B. A.; CORDEIRO, M. B.; COZZOLINO, S. M. F. Estimate of toxic element intake in diets of pre-school children and elderly collected by duplicate portion sampling. Food Add. Contam., v. 15, n. 7, p. 782-788, 1998.

[ 11 ] MAIHARA, V. A.; FÁVARO, D. I. T.; SILVA, V. N.; GONZAGA, I. B.; CUNHA, I. I. L.; VASCONCELLOS, M. B. A.; COZZOLLINO, S. M. F. Analysis of mineral constituents in duplicate portion diets of two university student groups by instrumental neutron activation analysis. J. Radioan. Nucl. Chem., v. 249, n. 1, p. 21-24, 2001.

[12] MONDINI, L.; MONTEIRO, C. A. Mudanças no padrão de alimentação da população urbana brasileira (19621988). Rev. Saúde Pública, v. 28, n. 6, p. 433-439, 1994.

[13] PROSKY, L.; ASP, N. G.; FURDA, I.; DEVRIES, J. W.; SCHWEIZER, T. F.; HARLAND, B. F. Determination of total dietary fibers in foods, food products and total diets: interlaboratory study. J. Assoc. Off. Anal. Chem., v. 67, n. 6, p. 1044-1052, 1984.

[14] YUYAMA, L. K. O.; AGUIAR, J. P. L.; MACEDO, S. H. M.; ALENCAR, F. H.; NAGAHAMA, D.; FÁVARO, D. I. T.; AFONSO, C.; VASCONCELlOS, M. A. B.; COZZOLINO, S. M. F. Avaliação da alimentação de pré-escolares de Barcelos e Ajuricabe, estado do Amazonas. Rev. Inst. Adolfo Lutz, v. 59, n. 1/2, p. 27-32, 2000.

\section{AGRADECIMENTOS}

À FAPESP pelo apoio financeiro (Projeto $n^{\circ}$ 99/12196-8), à Indústria MWM pelo fornecimento das dietas dos trabalhadores e à indústria Liotécnica pela liofilização das amostras. 